\title{
Metonymic Similes in Newspaper Film Reviews
}

\author{
Irina Vardanyan \\ Gyumri State Pedagogical Institute
}

$\mathrm{T}$ he review genre is well established in the form of literary reviews, traditionally published in print, where the reviewers express their opinions by commenting on the book and by telling the readers about their attitude towards it (Taboada 2011). Baud considers newspaper film reviews as a subgenre of literary reviews. Once films gained popularity, many of the conventions of the literary review genre were adopted by the film review genre, still appearing in print and written by professional film reviewers (Baud 2003).

A film review is not merely a short summary of a film but a critical analysis that examines whether it succeeds in its presentation. The evaluation part in the genre of a review is of great importance, since it emphasizes the merits and shortcomings of the work. The purpose of most film reviews is to help the audience determine whether they want to rent, buy, or see the film (Eliashberg and Shugan 1997). It strives to find expression for what is seen and heard, bringing the realm of sounds, actions and objects to meet a realm of words and concepts. From a review the audience can get roughly the content of a film as well as other information about it. According to Legget the most characteristic trait of film review is the announcement of judgments on the acting, story and cinematography (Legget 2005). Film review, on the other hand is considered a powerful marketing tool, or word-of-mouth information that has a strong impact on the reader's decision (Duan, Gu and Whinston 2008).

Mencher suggests that any film review comprises two main parts: basic information about the work (straight reporting) and the reviewer's assessment (the criticism) (Mencher 1996). The presence of informative and evaluative elements about the film can be explained by the fact that the reviewer who has seen the film tries to attract his readers' attention and aims to convince the reader to watch that particular film or not. Thus, the reviewer's job is to describe and judge a film the public is not familiar with and advise them on its merits.

Zhang, Dellarocas and Awad state that the style of writing and word choices are considered the most essential features to attract reader's interest (Zhang, Dellarocas and Awad 2004). Since the purpose of most film reviews is to help the reader make a decision about watching the film or not, the reviewer tries to make the review more persuasive and convincing, enriching it with different tropes and figures of speech. Among various figures of speech and tropes the linguistic phenomenon of simile has its own place in the texts of film review. Kirszner and Mandell in The Brief Holt Handbook define simile as a "comparison between two essentially unlike items on the basis of a shared quality" (Kirszner and Mandell 2000). This viewpoint is supported in The American Heritage College Dictionary where simile is framed as "a figure of speech in which two essentially different things are explicitly compared, usually by means of like or $a s "$ (1993). It must be noted that the difference between the simile and the metaphor 
lies in the meaning: in case of metaphor there is an advance of meaning, whereas in case of simile there is no transfer in meaning. Simile, as a figure of speech is patterned by specific combinations of words, syntactic constructions that are called to strengthen the expressiveness of speech.

The present research explores the role of metonymic similes in newspaper film reviews. Metonymic similes emphasize contiguity between two referents. Paradis defines metonymization as "the use of a lexical item to evoke the sense of something that is not conventionally linked to that particular lexical item" (Paradis 2004).

In metonymic similes the objects, phenomena, situations are compared in order to explain everything more clearly, give the account of the author's thoughts, bring the expressed thoughts close to the reader, and give him a chance to appreciate the author's ideas. Associations, lying on the basis of such comparisons, bring the limited number of physical characteristics, such as form, volume, dimensions, colors, etc. Metonymic similes are "two-stepped" because the words directly relate to the objects they denote and do not result in the creation of poetic images. They allow the reviewer to express his thought in an original and interesting way, as well as help the reporter grab his readers' attention.

It is noteworthy that metonymic similes are equally used both in informative and evaluative parts of film reviews.

Let us analyze some examples of metonymical similes, functioning in the part of straight reporting.

Despite Swinton disappearing into her part, the film rambles on and on , a bit like a shaggy dog yarn told by a drunk-engaging to begin with, but increasingly exasperating.

(Mirror, December 5, 2008)

To criticize long and pointless duration of the film, the reviewer compares it with " $a$ shaggy dog yarn", which is explained as an extremely long-winded tale featuring extensive narration of typically irrelevant incidents, to which the audience listens with certain expectations, which are either simply not met or met in some entirely unexpected manner.

The perception and interpretation of a simile depends not only on the reader's basic knowledge, life experience, and educational background, but also on the context, which bears much importance. It is the context that provides an opportunity to acknowledge meanings, which result from combining things and phenomena that greatly depend on the author's ideas, creative thinking and imagination.

With neither Liv nor Emma prepared to back down, friendship is tossed like a bridal bouquet and all-out war ensues. Plenty of shrieking, too.

(Mirror, January 8, 2009)

The simple and obtainable similes that Nigel Andrews and David Edwards use in the introductions of their reviews (for example, the fact that friendship is not only tossed like 
a bridal bouquet, but is turned into a battlefield at the first disagreement) especially help the reviewers render the film more vividly, thus making it possible for the reader to clearly imagine the plot of the film arousing their interest in the film itself.

The trailer for the movie just shows a bunch of young New Yorkers running for their lives as the head of the Statue of Liberty lands in their street, tossed like a bowling ball, amid sounds of approaching chaos and terror.

(The Daily Telegraph, January 13, 2008)

The reviewer of 'The Daily Telegraph' skillfully uses a metonymic simile in his review comparing the rolling head of the Statue of Liberty with a bowling ball. The reviewer writes in such a way as to bring the film into imaginative being for the reader, so that the reader views it in the process of reading. In reading he or she becomes a film viewer.

The use of such similes is peculiar to the genre of reviews as due to its imagery character, besides persuading and convincing the reader, it also provides information about the film realizing preaching or anti-preaching function. Thus every simile used in the genre of the film review carries out influential, cognitive, persuasive and preaching functions.

The data at our disposal reveal an excellent example of a metonymic simile functioning in evaluative part of the review.

\section{I can truthfully say that watching this abysmal fantasy-comedy is less rewarding than being slapped across the face with a large wet fish.}

(The Guardian, February 1, 2008)

The example adduced above is the introduction of the negative review published in 'The Guardian', which makes it clear that the reviewer intends not only to enrich it with emotionally coloured syntagmas, but also to achieve some anti-preaching effect. The reviewer's personal negative attitude towards the film is revealed in the metonymic simile "less rewarding than being slapped across the face with a large wet fish". The comparison made by the reviewer yields to disgusting associations. The readers with bright imagination would give up the idea of watching that particular film. It is apparent that with the help of such a simile the reviewer succeeds in providing his readers with some metacontent: the film is a blunder.

Linguists point out that each kind of a review presupposes a specific audience and a specific aim. When writing a film review, the reviewer always considers who the intended audience is for the film and the audience he is writing for.

In order to appreciate the value of some similes it is necessary that both the reviewer and the reader have the same background information, as the lack of it results in misunderstanding of the simile, thus making the right perception and interpretation of it impossible. 
Yuletide trappings here, though Demi Moore will do as the ghost of Hollywood past, rattling her jewelled accessories like a drag-queen Jacob Marley.

(The Times, November 26, 2008)

In order to understand the meaning of metonymic simile used by the reviewer the reader should have some background knowledge about Jacob Marley, whose spirit has to carry heavy chains of his own sin and greediness. This simile enables the reviewer to convey the image of the heroine more clearly and vividly.

Thus, the data at our disposal show that in order to grab the reader's attention and to arouse the necessary parallels in the reader's mind, the reviewers make use of metonymic similes in the texts of their reviews, especially in the introductory and evaluative parts, which help them get closer to their readers and establish reliable relations with them.

\section{References:}

1. The American Heritage College Dictionary (3rd ed.) (1993) Boston: Houghton Mifflin.

2. Baud, D. (2003) Analyse de genre: La critique de cinéma dans la presse quotidienne britannique. ASp: La revue du GERAS 39/40 (pp. 37-45).

3. Duan, W.; Gu, B. and Whinston, A.B. (2008) The Dynamics of Online Word-of-Mouth and Product Sales-An Empirical Investigation of the Movie Industry. // Journal of Retailing, 84 (2), (pp. 233-242).

4. Eliashberg, J. and Shugan, S.M. (1997) Film Critics: Influencers or Predictors? // Journal of Marketing. N 61 (April), (pp. 68-78).

5. Kirszner, L. and Stephen, M. (2000) The Brief Holt Handbook (3rd ed). Fort Worth: Harcourt Brace College Publishers.

6. Leggett, B.J. (2005) Convergence and Divergence in the Movie Review: Bonnie and Clyde. // Film Criticism 30(2), (pp. 1-23).

7. Mencher, M. (1996) Basic Media Writing (5th ed). Madison: Brown and Benchmark.

8. Paradis, C. (2004) Where does Metonymy Stop? Senses, Facets and Active Zones. // Metaphor and Symbol 19(4), (pp. 245-264).

9. Taboada, M. (2011) Stages in an Online Review Genre. // Text Talk, 31(2), (pp. $247-$ 269). Walter de Gruyter GmbH \& Co. KG.

10. Zhang, M.; Dellarocas, C. and Awad, N. (December 2004) The Impact of Online Movie Reviews on Box Office Performance. // Workshop on Information Systems and Economics (WISE), College Park, MD. 


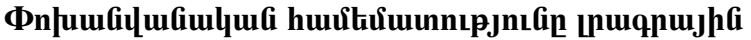 yhfinqpulununıpjuif intpuunnux}

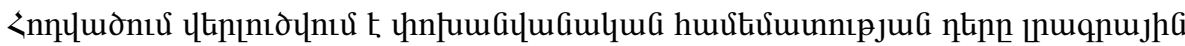

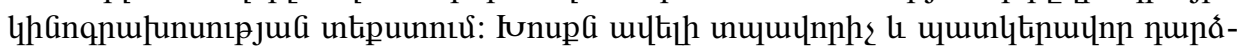

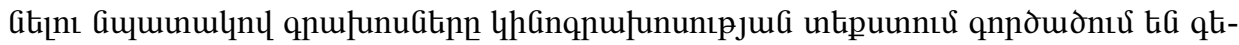

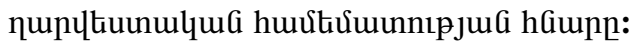

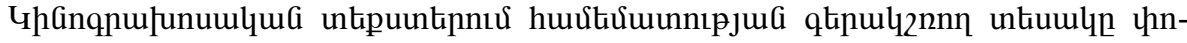

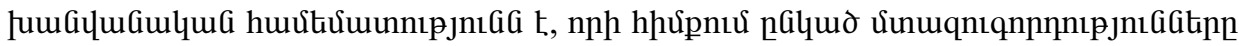

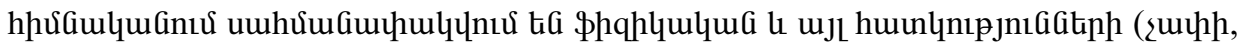

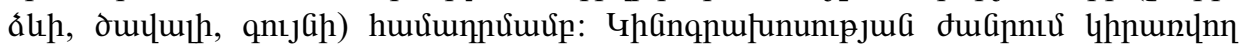

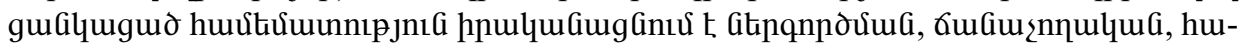

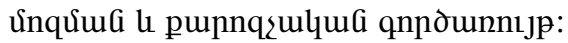

